\title{
Space Weather and Its Impact on Psycho-Emotional State of the Inhabitants of Different Latitudes
}

\author{
A. I. Kodochigova, $\mathrm{PhD}, \mathrm{ScD}^{1 *}$; S. S. Parshina, $\mathrm{PhD}, \mathrm{ScD}^{1}$; S. N. Samsonov, $\mathrm{PhD}^{2}$; \\ K. O. Belousova ${ }^{3}$; P. G. Petrova, $\mathrm{PhD}, \mathrm{ScD}^{4}$; A. A. Strekalovskaya, $\mathrm{PhD}^{4}$; \\ E. S. Olenko, $\mathrm{PhD}, \mathrm{ScD}^{1}$; D. Z. Psanukova ${ }^{1}$; T. N. Afanasyeva, $\mathrm{PhD}^{1}$ \\ ${ }^{1}$ Saratov State Medical University n.a. V.I. Razumovsky, Saratov, Russia \\ ${ }^{2} Y u$.G. Shafer Institute of Cosmophysical Research and Aeronomy, Siberian Branch of the RAS, \\ Yakutsk, the Republic of Sakha (Yakutia), Russia \\ ${ }^{3}$ The Ministry of Internal Affairs of the Russian Federation, Saratov Branch, Saratov, Russia \\ ${ }^{4}$ North-Eastern Federal University n.a. MK Ammosov, Yakutsk, the Republic of Sakha (Yakutia), Russia
}

\begin{abstract}
Purpose of the research was to conduct a comparative analysis of the psychological characteristics of the inhabitants of the northern and middle latitudes, depending on their psychological sensitivity to changes in geomagnetic disturbances

Materials and Methods: The study included 78 relatively healthy volunteers (women and men, the average age of 44.2[36.7; 54.3] years) living in the polar (Tiksi), subpolar (Yakutsk) and middle (Saratov) latitudes. Monitoring of the studied indicators was carried out during March and April 2016. To achieve this goal, the following methods were used: the Spielberger-Khanin scale for reactive (situational) and personal anxiety; E. Heim's technique for revealing individual coping strategies; the projective psychogeometric test. Every day, during March and April 2016, the Kp-index, an integral indicator of changing geomagnetic disturbance was used. Depending on the identified matches, the peak values of the reactive anxiety by Spielberger-Khanin and Kp-index (not less than $60 \%$ of cases), all volunteers were divided into 2 groups. Group 1 included persons with similar overlap and, therefore, carriers of psychological sensitivity to changes in the action of heliogeomagnetic factors. Group 2 included persons without a specified sensitivity (i.e., no coincidences).

Results: In the course of the study, both coinciding and latitude-related differences in the psychological characteristics of different groups of volunteers were established. In the inhabitants of the polar and subpolar latitudes, especially in Group 1, the behavioral sphere was the most vulnerable (no constructive coping strategies). In addition, their changes in the emotional sphere contributed to the manifestation of aggressiveness and suppression of emotions against the background of general concentration, purposefulness and integrity of the individual. Regardless of the latitude of residence, volunteers, psychologically sensitive to changes in heliogeomagnetic factors, were more constructive in the emotional sphere, and the least in the behavioral, which gives reason to state that, depending on the factors of space weather, the behavior of the individual is the most vulnerable.(International Journal of Biomedicine. 2018;8(4):311-316.)
\end{abstract}

Key Words: heliogeomagnetic factors $\bullet$ anxiety $\bullet$ coping behavior $\bullet$ psychological sensitivity $\bullet$ multi-latitude monitoring

\section{Introduction}

"We all live in the crown of the Sun" is the indisputable thesis of A.L. Chizhevsky. But how is human health related to changes in solar activity and the geomagnetic field? The full answer to this question has not yet been found.

From 2003 to 2010, through the joint efforts of physicists, physicians, psychologists, information technology specialists, and biologists, a unique, large-scale international telecommunication project "Heliomed" was carried out, where the impact of space weather on the human body was studied by a single online protocol, on identical equipment, in medical centers located at different latitudes. ${ }^{(1)}$

Since 2014, the village of Tiksi (polar latitude) and the cities of Yakutsk (subpolar latitude) and Saratov (middle latitude) have been undergoing multi-latitude monitoring aimed at studying the influence of space weather factors on the nervous and cardiovascular systems of relatively healthy 
volunteers, which was a continuation of the "Heliomed" project. ${ }^{(2)}$ Stages of monitoring are held in the periods of maximal activity of the heliogeophysical factors - fall and/ or spring.

Tiksi and Yakutsk are located in the territory of the Republic of Sakha (Yakutia). It is interesting that in this region in a wide range of longitude there is the greatest difference in the slopes of the Earth's axis of rotation and the axis of its geomagnetic field, which is about $11^{\circ}$. On our planet, there is only one region with similar properties, but because it is located in the Atlantic Ocean, research cannot be conducted there, and, consequently, the results obtained in the course of this monitoring acquire special scientific value.

Recently, a major role in the development of socially significant pathology, including cardiovascular disease, which is the «culprit» of high morbidity and mortality in the adult population of the planet, is played by stress and emotionally negative risk factors (such as depression, increased level of neurotization, anxiety and a number of others). ${ }^{(3-7)}$ In addition, it has been shown that the same elevated levels of neurotization, depression and anxiety in clinically healthy individuals can be a significant risk factor for diseases in the pathogenesis of which vasomotor dysfunction of the endothelium is the trigger. ${ }^{(8)}$

Data on the assessment of the psycho-emotional status of persons under the influence of space weather factors in the domestic and foreign literature are not widely presented. In fact, a detailed study of the effect of heliogeomagnetic disturbances on the psycho-emotional state of volunteers has not been carried out; and there is no such study that takes into account the nature of the subjects' choice of coping strategy in stressful situations with differentiation by spheres, their levels of anxiety, and personality type. Previously, we have substantiated in detail the methodological approaches to the choice of methods for assessing the impact of space weather on the psycho-emotional state of volunteers, allowing us to determine the most accurate features of the psycho-emotional status of the subjects. ${ }^{(9)}$

Purpose of the research: To conduct a comparative analysis of the psychological characteristics of the inhabitants of the northern and middle latitudes, depending on their psychological sensitivity to changes in geomagnetic disturbances

\section{Materials and Methods}

The study included 78 relatively healthy volunteers (women and men, the average age of $44.2[36.7 ; 54.3]$ years) living in the polar (Tiksi), subpolar (Yakutsk) and middle (Saratov) latitudes.

Monitoring of the studied indicators was carried out during March and April 2016.

Inclusion criteria: males and females; relative health at the time of observation.

Exclusion criteria: cognitive impairment of different nature; the use of psychotropic and psychoactive substances; acute forms of disease; chronic diseases in the acute stage; surgical interventions during the last 3 months; cancer pathology; multiple organ failure of different genesis; psychosomatic diseases.

To achieve this goal, we have used the following methods:

- The Spielberger-Khanin scale for reactive (situational) and personal anxiety ${ }^{(10,11)}$

- E. Heim's technique for revealing individual coping strategies $(12,13)$

- The projective psycho-geometric test ${ }^{(14,15)}$

A Spielberger-Khanin questionnaire is focused on the differential measurement of anxiety as a state (reactive or situational anxiety) and personal characteristics (personal anxiety or an anxious disposition).

The E. Heim test allows determining the style of dealing with stress. Heim's technique for psychological diagnosis of coping strategies makes it possible to explore 26 situationspecific options for responding to a complex situation, distributed in accordance with the three main spheres of mental activity: cognitive, emotional and behavioral.

The projective technique, based on a psycho-geometric approach, allows one to instantly determine the form or type of personality and to give a detailed description of the psychological qualities and peculiarities of human behavior in typical situations.

The first part of the Spielberger-Khanin test (to determine reactive anxiety) was presented to the project participants during the entire observation phase. The remaining tests were given once: at the initial stage of the study phase. Every day, during March and April 2016, the Kp-index, an integral indicator of changing geomagnetic disturbance was used.

The study was conducted in accordance with ethical principles of the WMA Declaration of Helsinki (1964, ed. 2013). Written informed consent was obtained from all participants.

Statistical analysis was performed using StatGraph Plus for Windows 6.0 software package. The normality of distribution of continuous variables was tested by the Kolmogorov-Smirnov test with the Lilliefors correction and Shapiro-Wilk test. Differences of continuous variables departing from the normal distribution were tested by the Mann-Whitney $U$-test. A probability value of $P<0.05$ was considered statistically significant.

\section{Results}

Depending on the identified matches, the peak values of the reactive anxiety by Spielberger-Khanin and Kp-index (not less than $60 \%$ of cases), all volunteers were divided into 2 groups. Group 1 included persons with similar overlap and, therefore, carriers of psychological sensitivity to changes in the action of heliogeomagnetic factors. Group 2 included persons without a specified sensitivity (i.e., no coincidences).

Results of psychological examination of the inhabitants of the middle latitudes

According to the results of the psychological examination of the inhabitants of the middle latitudes, $44.4 \%$ of the observed individuals were included in Group 1 and 55.6\% in Group 2. The peculiarities of coping behavior according to the given situation are shown in Figs.1-3. During the Heim test in Group 1 , we found that constructive coping strategies were dominant 
in the emotional sphere $(P=0.04$, Fig. 2$)$, non-constructive strategies - in the behavioral sphere $(P=0.04$, Fig.3), and the constructive and non-constructive coping strategies were chosen at approximately the same frequency in the cognitive sphere (Fig. 1). In Group 2, constructive coping strategies prevailed in cognitive $(P=0.04$, Fig. 1$)$ and emotional $(P=0.04$, Fig.2) spheres; when constructing the actual coping behavior, both constructive and non-constructive options were often used equally (Fig. 3). Our analysis of the choice of coping strategies with differentiation by spheres found that volunteers of Groups 1 and 2 chose, from among the constructive coping strategies in the cognitive sphere, maintaining self-control (33.3\% and $33.0 \%$, respectively), cultivating high self-esteem (33.3\% and $17.0 \%$, respectively), and problem analysis; the last coping reaction was chosen most often in Group $2(50.0 \%)$. Among the non-constructive coping strategies, ignoring (33.3\%), dissimulation (33.3\%), and confusion (33.4\%) were revealed in individuals of Group 1; Group 2 individuals (100\%) preferred to ignore the problems. In the emotional sphere, most of the observed persons were optimistic (Group $2-100 \%$, Group $1-75 \%$ ); protest was chosen by $25 \%$ of individuals of Group 1. From non-constructive emotional coping reactions, volunteers of Group 1 preferred obedience(100\%), and Group 2 individuals - obedience and suppression of emotions (50\% and $50 \%$, respectively). Building their own coping behavior, Group 1 individuals, when choosing non-constructive coping strategies, preferred to retreat in the face of difficulties $(75,0 \%)$ or actively avoid them $(25,0 \%)$; and choosing constructive strategies, preferred to cooperate with persons who were significant for them (100\%). Group 2 individuals, when choosing non-constructive coping strategies, tried to avoid problems (in 100\%), and when choosing constructive strategies, cooperated with persons significant for them $(66.7 \%)$ or turned to them for help (33.3\%).
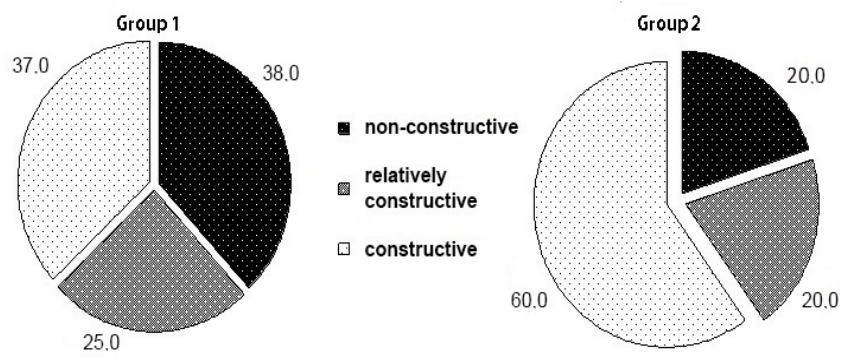

Fig. 1. Coping strategies in the cognitive sphere in the inhabitants of the middle latitudes (\%).

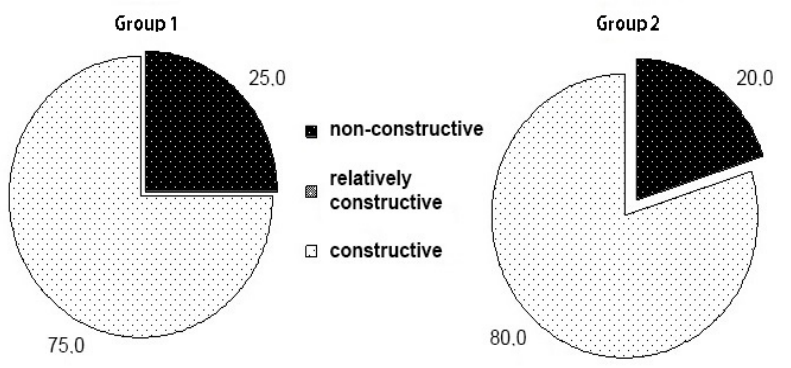

Fig. 2. Coping strategies in the emotional sphere in the inhabitants of the middle latitudes (\%).
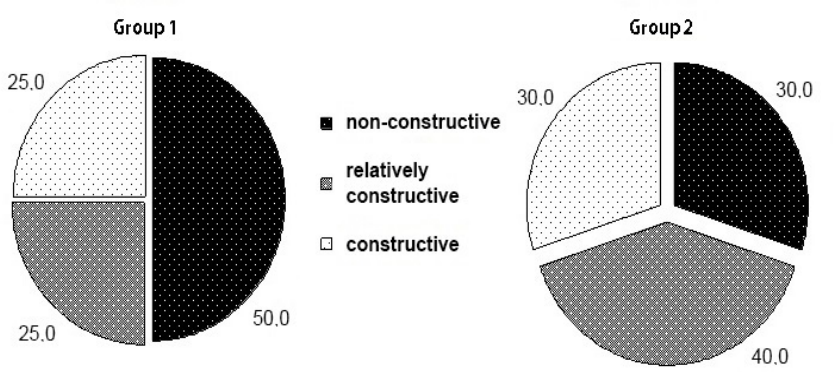

Fig. 3. Coping strategies in the behavioral sphere in the inhabitants of the middle latitudes (\%).

Psycho-geometric test results with the stimulus material are presented in Figs. 4-5. Thus, Group 1 individuals preferred, among other geometric shapes, a circle $(63.0 \%)$, rejecting a zigzag (75.0\%); Group 2 individuals chose a triangle and a circle ( $40 \%$ in both cases), rejecting the circle and zigzag (30\% in both cases) (Figs. 4-5).

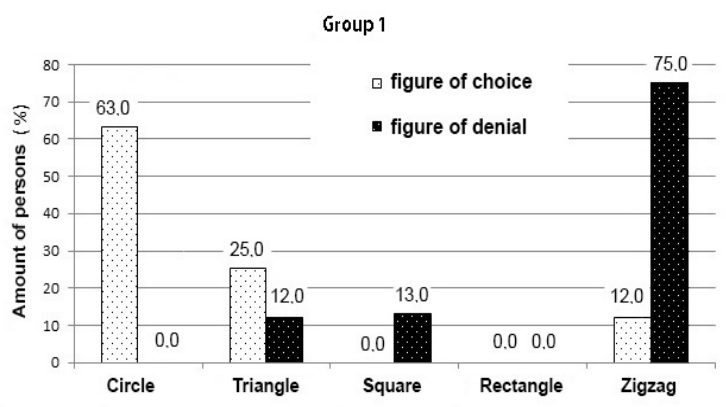

Fig. 4. Psycho-geometric test results in Group 1 individuals of the middle latitudes.

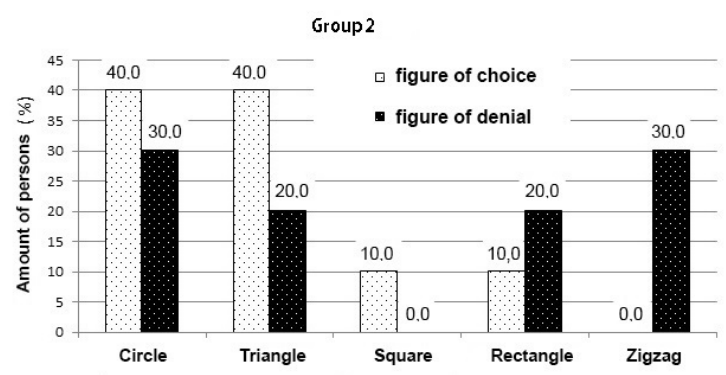

Fig. 5. Psycho-geometric test results in Group 2 individuals of the middle latitudes.

\section{Results of psychological examination of the inhabitants of the} auroral and sub-auroral latitudes

According to the results of psychological examination of people of the auroral and sub-auroral latitudes, $55.6 \%$ of the observed individuals were included in Group 1 and $44.4 \%$ in Group 2.

The construction of coping behavior in the cognitive, emotional and behavioral spheres in the inhabitants of the northern latitudes is illustrated in Figs. 6-8. Volunteers of both groups preferred constructive coping reactions in the cognitive sphere ( $P \leq 0.05$, Fig. 6). In the emotional sphere, constructive 
coping strategies were chosen more often in Group 1, and nonconstructive strategies in Group 2 (Fig.7). In the behavioral sphere, constructive coping strategies were absent in Group I, and only $9.0 \%$ in Group 2; thus, non-constructive strategies were more often chosen in Group 1 than Group 2 ( $P \leq 0.04$, Fig. 8).

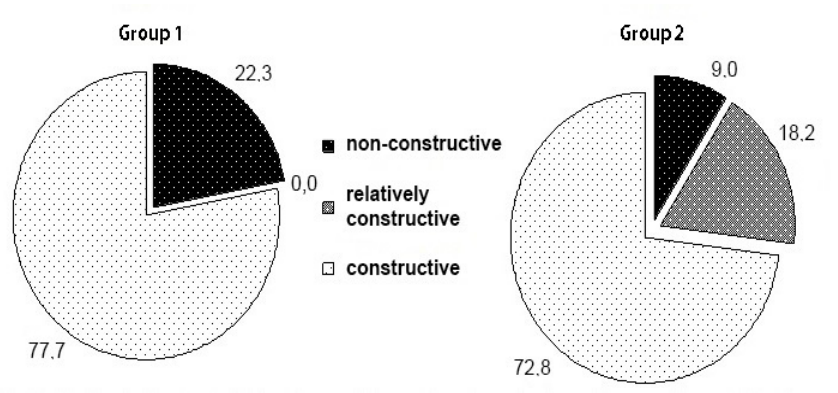

Fig. 6. Coping strategies in the cognitive sphere in the inhabitants of the northern latitudes (\%).

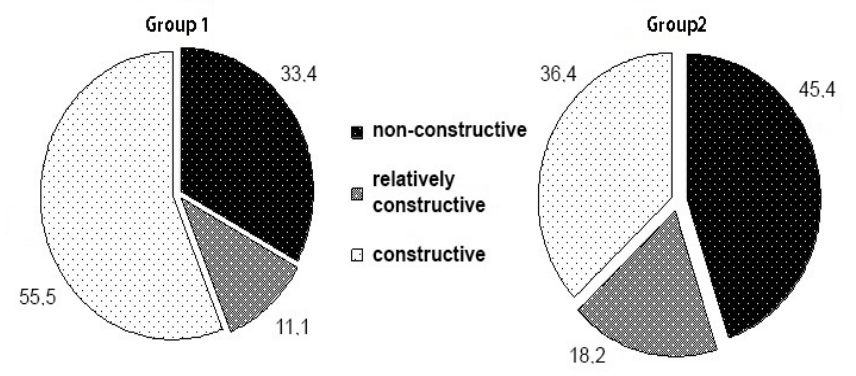

Fig. 7. Coping strategies in the emotional sphere in the inhabitants of the northern latitudes (\%).
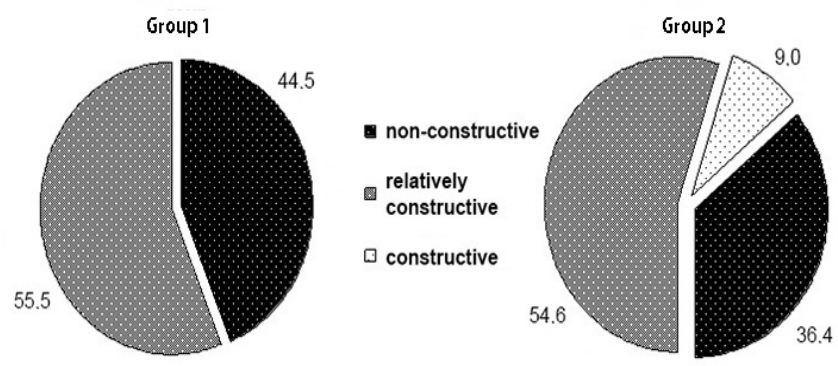

Fig. 8. Coping strategies in the behavioral sphere in the inhabitants of the northern latitudes (\%).

Our analysis of the choice of coping strategies with differentiation by spheres found that the most common cognitive constructive coping strategies in Group I were maintaining self-control (71.5\%) and problem analysis, which was found in $28.5 \%$. In Group 2, on the contrary, problem analysis $(87.5 \%)$ was more common, and maintaining selfcontrol was found in $12.5 \%$. In volunteers of both groups, optimism prevailed among constructive emotional coping reactions (Group $1-100 \%$, Group $2-75.0 \%$ ), and in Group $2,25.0 \%$ of monitoring participants chose protest. Of the nonconstructive emotional coping styles, representatives of both groups preferred suppression of emotion (Group $1-66.7 \%$, Group $2-100 \%)$. At the same time, Group 1 individuals, in some cases, showed aggression (33.3\%). In the behavioral sphere, constructive coping strategies were absent in Group 1 ; at the same time, Group 2 persons used altruism and careseeking equally. As for non-constructive behavioral coping strategies, all persons of Group 1 used active avoidance, and persons of Group 2, in most cases, chose retreat (75.0\%), and less often, active avoidance (25.0\%).

In the psycho-geometric test, Group 1 individuals preferred, among other geometric shapes, a circle and a triangle (33.3\% in both cases), rejecting a zigzag (55.5\%) (Fig. 9). Group 2 persons preferred the square and triangle $(40.0 \%$ and $30.0 \%$, respectively), also rejecting a zigzag (70.0\%) (Fig. 10).

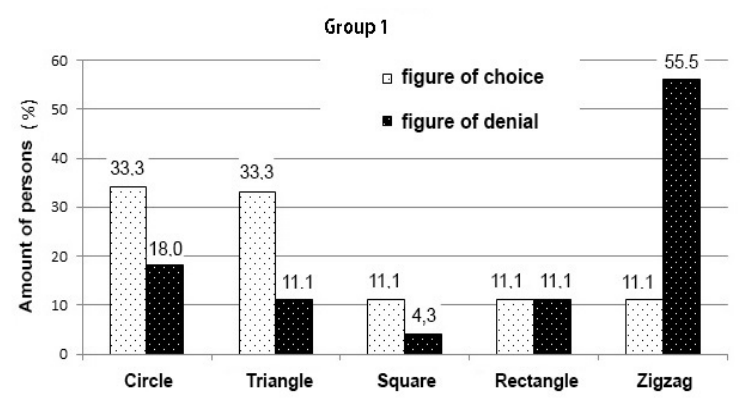

Fig. 9. Psycho-geometric test results in Group 1 individuals of the northern latitudes.

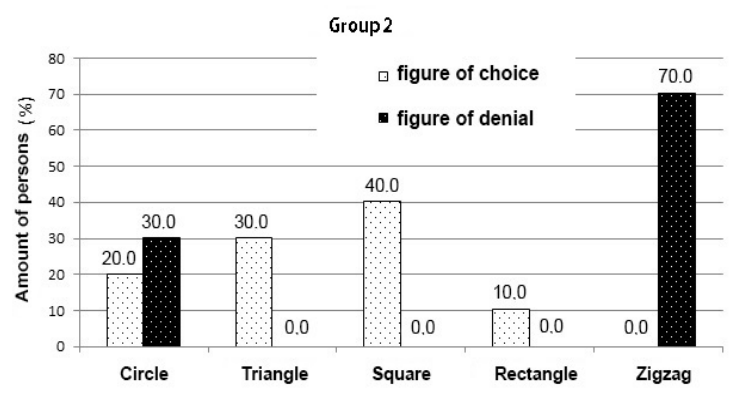

Fig. 10. Psycho-geometric test results in Group 2 individuals of the northern latitudes.

\section{Discussion}

Based on the results obtained, psychological portraits of the inhabitants of the middle latitudes, depending on the presence or absence of their psychological sensitivity to the actions of heliogeomagnetic factors, can be presented as follows: Group 1 representatives, facing a stressful situation and building their coping behavior, are the most constructive in the emotional sphere: they are optimistic, friendly, do not tend to suppress either their positive emotions or negative emotions, and are ready to protest, if necessary. Group 2 representatives are also the most constructive in the emotional sphere, as optimistic as persons from Group I, but unlike the latter, tend to suppress their emotions without expressing active protest against negative circumstances.

Representatives from both groups living in the middle latitudes, in some cases, can be submissive under the influence 
of negative factors, but only persons of Group 1 are able to protest against hostile circumstances, while Group 2 persons suppress their emotions.

In the cognitive sphere, representatives of Group 2 turned out to be more constructive, preferring problem analysis. Representatives of Group 1 also, although to a lesser extent, are able to pay attention to assessing cause-effect relationships and emerging problems, along with maintaining self-control and self-esteem.

In both groups, the most problematic coping sphere among residents of middle latitudes was the behavioral sphere, which most clearly manifested in Group 1. Group 1 persons are prone to retreat and less likely to avoid problems, while Group 2 persons always actively avoid problems and difficulties.

The constructive behavior of the representatives of both groups living in the middle latitudes is mainly expressed in cooperation with persons of importance to them.

The above-mentioned psychological characteristics of Group 1 individuals can be complemented with their sociability, delicacy, friendliness, hospitality, flexibility and the desire to avoid conflicts (mainly the choice of the circle and the denial of the zigzag at psychosomatic testing).

In Group 2 individuals, purposefulness, leadership traits, activity, and sometimes conflictedness, as well as contradictory personality traits, can serve as a supplement to their psychological portrait.

The inhabitants of the northern latitudes - representatives of both groups - are the most constructive in the cognitive sphere. Self-control and, in part, the desire to analyze the problems were dominant in Group 1. In Group 2, the dominant coping cognition was a problem analysis and, to a much lesser extent, maintaining self-control. In the emotional sphere, the representatives of Group 1 were more constructive than in Group 2. At the same time, optimism dominated in both groups, especially in Group I, and the representatives of Group 2 sometimes protested against negative circumstances. Quite often in Group I and always in Group 2, the inhabitants of polar and subpolar latitudes suppressed their emotions, and Group 1 volunteers, from time to time, experienced aggression. In the representatives of both groups, the most unfavorable situation was in the construction of the actual coping behavior: There were no constructive behavioral coping strategies completely in Group 1 (these persons preferred to avoid problems exclusively); there were few constructive coping strategies in Group 2, and their non-constructive behavior was represented mainly by retreat and, in part, active avoidance.

The personality traits of Group 1 individuals can be complemented with their sociability, responsibility, purposefulness, concentration and lack of contradiction of psychological characteristics. In Group 2, those traits are restraint, propensity to individual activities, logical reasoning, diligence, conservatism, and conformity.

\section{Conclusion}

Thus, in 2016, in the northern and middle latitudes, the distribution of persons who were psychologically sensitive and insensitive to changes in heliogeomagnetic factors did not differ significantly and was approximately equal. In the course of the study, both coinciding and latitude-related differences in the psychological characteristics of different groups of volunteers were established.

In the inhabitants of the polar and subpolar latitudes, especially in Group 1, the behavioral sphere was the most vulnerable (no constructive coping strategies). In addition, their changes in the emotional sphere contributed to the manifestation of aggressiveness and suppression of emotions against the background of general concentration, purposefulness and integrity of the individual. Regardless of the latitude of residence, volunteers, psychologically sensitive to changes in heliogeomagnetic factors, were more constructive in the emotional sphere, and the least in the behavioral, which gives reason to state that, depending on the factors of space weather, the behavior of the individual is the most vulnerable.

\section{Conflict of interest}

The authors declare that they have no competing interests.

\section{References}

1. Biotropic effects of space weather (based on the materials of Russian-Ukrainian monitoring "Heliomed" 2003-2010). In: M.V. Ragul'skaya, editor. M., Kiev-St. Petersburg: VVM, 2010. [In Russian].

2. Parshina SS, Samsonov SN, Manykina VI, et al. [Features of the group reaction of cardiovascular system to changes of space weather]. Materials of the International conference IT+M\&Ec; New Information Technologies in Medicine, Biology, Pharmacology and Ecology. M.;2015 316-322. [Article in Russian].

3. Gromova EA. [Psychosocial risk factors for cardiovascular diseases (literature review)]. Siberian Medical Journal 2012;(2):22-29. [Article in Russian].

4. Chapala TV. Psychological risk factors in clinical dynamics of coronary heart disease. Abstract of PhD Thesis. St. Petersburg; 2012. [In Russian].

5. Kodochigova A. I. Psycho-physiological criteria of the risk of development of arterial hypertension and coronary heart disease. Abstract of ScD Thesis. Saratov; 2005. [In Russian].

6. Kirichuk VF, Kodochigova AI, Mareeva TI, Olenko ES, Demina TM, Martynova AG, et al. [Copping behavior of clinically healthy persons and patients with arterial hypertension devoting to various social groups and adaptive reserves of their cardiovascular system]. Saratov Journal of Medical Scientific Research. 2009;5(1):108-111. [Article in Russian].

7. Katsarou AL, Triposkiadis F, Panagiotakos D. Perceived stress and vascular disease: where are we now? Angiology. 2013;64(7):529-34. doi: 10.1177/0003319712458963.

8. Kirichuk VF, Olenko ES, Kodochigova AI, Barylnik YB, Deeva MA, Bazhenov VA. [Vasomotor Endothelial Function in Healthy Individuals: Contact Types of Character].Fiziol Cheloveka. 2015;41(3):106-11. [Article in Russian].

*Corresponding author: Prof. Anna I. Kodochigova. PhD, ScD. Saratov State Medical University n.a. V. I. Razumovsky. Saratov, the Russian Federation. E-mail: kodochigovaai@yandex.ru 
9. Kodochigova AI, Parshina SS, Samsonov SN, Afanasyeva TN, Olenko ES. Justification for methodological approaches to assessing the impact of space weather on psycho-emotional state of volunteers. Psychosomatic and Integrative Research. 2016;2(1):0105.[Article in Russian].

10. Karandashev VN, Lebedev MS, Spielberger CD. Evaluation of anxiety: a guide to use. St. Petersburg; 2004. [In Russia].

11. Khanin YL. A brief guide to the use of a scale of reactive and personal anxiety by Ch.D. Spielberger. Leningrad.: LNII FC; 1976. [In Russian].

12. Heim E. [Coping and psychological adaptation: is there appropriate and inappropriate coping?]. Psychother Psychosom
Med Psychol. 1988;38(1):8-18. [Article in German]. 13. Karademas EC, Tsalikou C, Tallarou MC. The impact of emotion regulation and illness-focused copying strategies on the relationship of illness-related negative emotions to subjective health. J Health Psychol. 2011;16(3):510-9. doi: 10.1177/1359105310392093.

14. Dellinger S. Psychogeomtrics. Psychogeomtrics: How to Use Geometric Psychology to Influence People. New Jersey: Prentice-Hall; 1989.

15. Garber EI, Kozacha VV. Psychogeometric testing (theoretical and practical aspects). Saratov: Scientific Book; 1999. [In Russian]. 